\title{
A comparison between the chemical behaviour of lead-gold and lead-bismuth eutectics towards 316L stainless steel
}

\author{
By S. Heinitz ${ }^{1,5}$, D. Schumann ${ }^{1, *}$, J. Neuhausen ${ }^{1}$, S. Köchli1 ${ }^{1}$, K. Thomsen² ${ }^{2}$ E. Platacis ${ }^{3}$, O. Lielausis ${ }^{3}$, I. Bucenieks ${ }^{3}$, \\ A. Zik ${ }^{3}$, A. Romančuks ${ }^{3}$, K. Kravalis ${ }^{3}$, L. Buligins ${ }^{4}$ and A. Türler ${ }^{1,5}$ \\ ${ }^{1}$ Paul Scherrer Institute, Laboratory of Radiochemistry and Environmental Chemistry, 5232 Villigen, PSI, Switzerland \\ 2 Paul Scherrer Institute, Spallation Neutron Source Division, 5232 Villigen, PSI, Switzerland \\ ${ }^{3}$ Institute of Physics, University of Latvia, 2169 IPUL, Latvia \\ ${ }^{4}$ Faculty of Physics and Mathematics, University of Latvia, 1002 Riga, Latvia \\ 5 University of Bern, Department of Chemistry and Biochemistry, 3012, Bern, Switzerland
}

(Received November 26, 2012; accepted in revised form February 28, 2013)

(Published online October 7, 2013)

\section{Corrosion / LGE / LBE / Isothermal / SS 316L / Liquid metal / Spallation target}

\begin{abstract}
Summary. Lead-gold eutectic (LGE) has been recently proposed as an alternative target material for high power spallation sources. In order to compare the corrosive properties of LGE to the better-studied eutectic of lead-bismuth (LBE), an isothermal twin-loop made of SS 316L was built and operated at the Institute of Physics of the University of Latvia. We have measured the concentration of steel alloying elements dissolved in both alloys at the end of two test campaigns via ICP-OES. In case of LGE, a pronounced concentration increase of $\mathrm{Fe}, \mathrm{Ni}, \mathrm{Mn}$ and $\mathrm{Cr}$ is found in the liquid metal, which is significantly higher compared to LBE. Similar results were obtained during complementary investigations on material samples exposed to both alloys in this twin-loop at $400{ }^{\circ} \mathrm{C}$ and $450{ }^{\circ} \mathrm{C}$. These findings indicate that in contact with LGE, SS 316L steel suffers from substantial chemical attack. Detailed investigations using structure materials other than SS 316L have to be undertaken before qualifying LGE as a serious alternative to LBE.
\end{abstract}

\section{Introduction}

The use of heavy liquid metals as target materials and coolants in nuclear facilities is currently a topic under intense investigation. For spallation sources with beam powers exceeding the megawatt range, liquid metal targets can offer several advantages over solid targets. Facilities operating with liquid metals may achieve comparable neutron fluxes while having similar neutronic and better heat dissipation performance. Additionally, the liquid metal target material itself does not suffer from irradiation damage. Therefore, the exchange frequency of such a target is determined more by the lifetime of the target containment, especially the proton beam window [1].

For high power spallation sources, the materials taken into consideration are mercury, lead and its eutectic alloy

\footnotetext{
*Author for correspondence (E-mail: dorothea.schumann@psi.ch).
}

with bismuth, lead-bismuth eutectic (LBE). Currently two spallation sources operating with mercury exist in the US (SNS, ORNL, [2]) and in Japan (J-PARC, JAERI, [3]). Mercury was also considered as a possible target material for the European Spallation Source (ESS, Sweden, [4]) in the past, but has currently been dropped due to serious disposal issues, since there is no proven technology for solidification and storage of large amounts of radioactive mercury [5].

In order to avoid problems arising from mercury, lead and LBE have been discussed as possible alternative materials for liquid metal targets. The bismuth-based alloy features the advantage of having a considerably lower melting temperature compared to pure lead. This allows the facility to be run at a lower operating temperature, thus reducing engineering challenges and diminishing corrosion effects on structure materials and increasing their lifetime. A demonstration experiment (MEGAPIE) using LBE as target material was successfully performed at PSI, Switzerland, in 2006 [6]. LBE is currently foreseen as coolant and spallation material in the MYRRHA demonstration reactor to be build at SCK-CEN, Belgium [7]. The ESS project as well has considered LBE as a possible fallback solution.

The use of LBE, however, does not come without certain drawbacks. Due to nuclear reactions of bismuth, a considerable amount of ${ }^{208-210} \mathrm{Po}$ is formed within the liquid metal [1]. Being a volatile $\alpha$-emitter, polonium poses serious radiation safety issues during operation of the facility and disposal of the target material. Additionally, a volume increase after solidification is observed for LBE, which may cause serious damage to the facility due to tube ruptures in case the liquid metal accidentally solidifies [8].

In order to circumvent these problems, a eutectic mixture of lead and gold (LGE, $T_{\mathrm{m}}=212.5^{\circ} \mathrm{C}, 84.1$ at. \% $\mathrm{Pb}, 15.9$ at. \% $\mathrm{Au}$ [9]) was suggested as alternative target material $[10,11]$. While having similar neutronic performance, LGE does not exhibit a volume increase in the solid state [11]. The accumulation of Po isotopes was calculated to be in the order of $10^{4}$ less compared to LBE, if no impurity bismuth is present [11]. However, the advantages of 


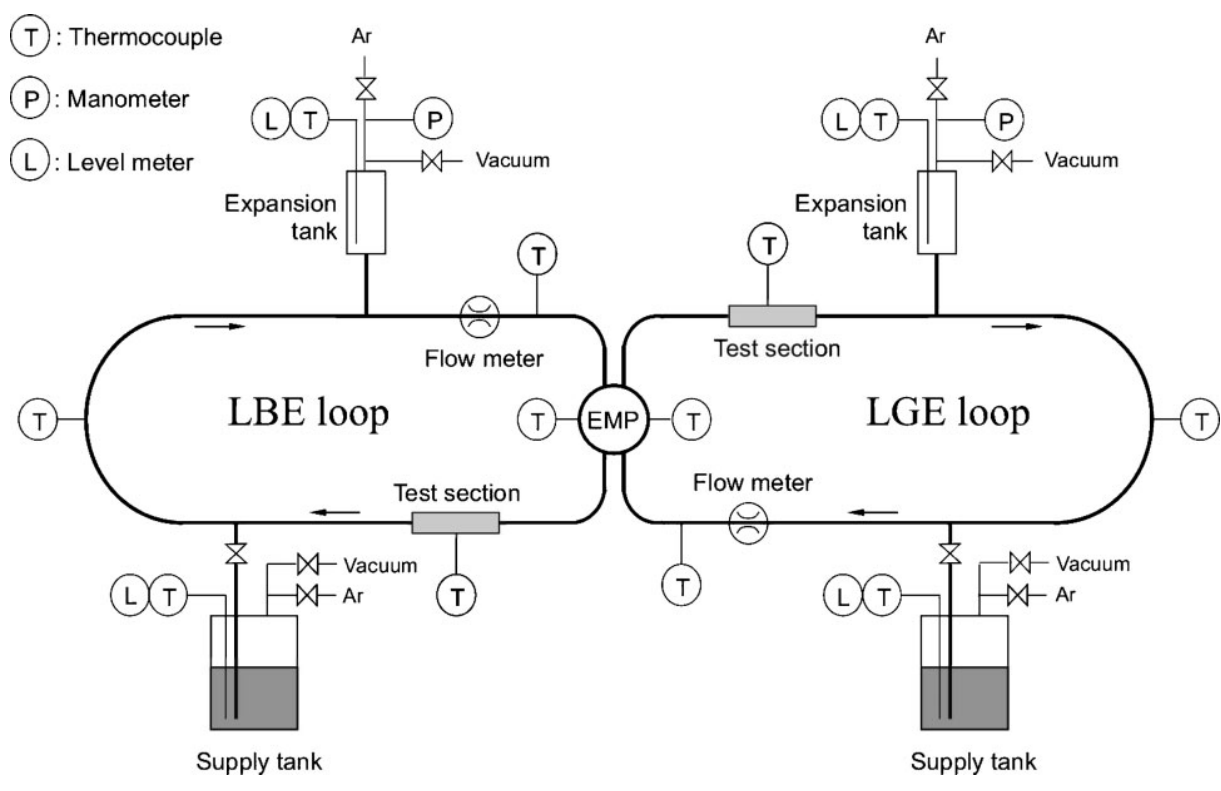

Fig. 1. Schematic layout of the twinloop.
LGE have to be outstanding to warrant the cost of this expensive material ${ }^{1}$.

Only few experimental data on properties of LGE relevant for nuclear applications are available up to now. Substantial R\&D has to be invested before LGE can be accepted as a serious alternative to LBE. One of these concerns is the evaluation of the corrosive behaviour of LGE towards structure materials.

In order to test the behaviour of flowing LGE towards steel structures and to compare it to LBE, two identical isothermal test loops were built and operated in Salaspils by the Institute of Physics of the University of Latvia (IPUL). It has to be pointed out that this study was not devoted towards detailed investigations on corrosion mechanisms in LGE, nor to elucidate precisely the physico-chemical aspects of the dissolution processes. In the absence of a number of monitoring tools, the aim of this study rather was to qualitatively assess the corrosive properties of LGE by comparing it to the better-known LBE in an experiment under identical conditions as far as possible.

Up to now, two campaigns operating at different temperatures were carried out and were chemically analyzed. The corrosive behaviour during these runs was investigated by applying two different methods. Analysis of steel specimens inserted in both loops was performed using scanning electron microscopy (SEM) in [12]. In the paper at hand, we report the concentrations of dissolution products present within both liquid metals after the two campaigns, measured using inductively coupled plasma optical emission spectroscopy (ICP-OES).

\section{Experimental}

Lead-bismuth eutectic was obtained as bars provided by GMH Jost-Hinrich Stachow GmbH, Goslar, Germany.

\footnotetext{
${ }^{1}$ In 2012, the market price of $1 \mathrm{~kg} \mathrm{Au}$ was around 50000 USD. For a 40-ton LGE target with $15 \mathrm{wt} \% \mathrm{Au}$ one would have to pay around 300 Mio USD, while 20 tons of Bi would cost only 400000 USD.
}

For the preparation of the eutectic lead-gold mixture a special mixing apparatus was developed by IPUL, where molten lead was added to molten gold in a controlled manner. Lead heated to $520^{\circ} \mathrm{C}$ in a steel vessel was added to molten gold at $1100{ }^{\circ} \mathrm{C}$ in a crucible made of Alsint $\mathrm{Al}_{2} \mathrm{O}_{3}$ ceramic material. During the mixing procedure, the apparatus was held under an argon atmosphere to avoid oxidation of molten lead.

In order to obtain a homogeneous alloy, the liquid metal in the ceramic crucible was thoroughly mixed by means of an electro-magnetic rotary induction stirrer. $862 \mathrm{~g}$ of gold, $99.99 \%$ purity, provided by Valcambi Inc., were mixed with 99.9\% lead, GMH Jost-Hinrich Stachow GmbH, to obtain $6 \mathrm{~kg}$ of LGE in three subsequent batches. The concentration of impurities inside the initial metals was determined by a procedure described below. The eutectic composition of the final product was confirmed by differential calorimetric measurements. The appearance of a plateau at $216^{\circ} \mathrm{C}$ during heating and cooling of the alloy coincided well with the expected LGE melting temperature.

Corrosion experiments were performed with two identical isothermal liquid metal loops. A schematic layout of this twin-loop is shown in Fig. 1.

The tubing of the twin-loop was made of $316 \mathrm{~L}$ stainless steel and had a length of approx. $2.5 \mathrm{~m}$ with an inner diameter of $10 \mathrm{~mm}$. Each loop was filled with approx. $200 \mathrm{~mL}$ of liquid metal from a supply tank. An electromagnetic pump (EMP) circulated the metals at a speed of $1 \mathrm{~m} / \mathrm{s}$ during two test campaigns performed at 400 and $450{ }^{\circ} \mathrm{C}$. At the end of each campaign, both alloys were drained back into the supply tanks, cooled down and solidified. There was no exchange of the alloys; the second test run was performed with the same material used in the run before. No oxygen sensor was present in either of the loops.

Additionally, a material test section was installed in each loop in order to investigate the corrosion behaviour of LGE and LBE towards austenitic 316LN and martensitic T91 stainless steel specimens. Both steel types are standard materials in existing spallation target facilities. After both runs, a maintenance break allowed the exchange of specimens in- 
Table 1. Impurity concentration of elements found in pure $\mathrm{Pb}$ and $\mathrm{Au}$ as well as in both investigated alloys for different loop temperatures and sampling times. The analysed steel composition is shown in the last row of the table. Values denoted by " $<$ " were below the quantification limit of the ICP-OE spectrometer. The overall errors were in the range of $\pm 20 \%$.

\begin{tabular}{|c|c|c|c|c|c|c|c|c|c|}
\hline \multirow{2}{*}{$\begin{array}{l}\text { Loop } \\
\text { temperature }\end{array}$} & \multirow{2}{*}{$\begin{array}{c}\text { Sampling } \\
\text { time after } \\
\text { startup }\end{array}$} & \multirow{2}{*}{$\begin{array}{l}\text { Analyzed } \\
\text { alloy }\end{array}$} & \multicolumn{7}{|c|}{ Impurity concentration [mass ppm] } \\
\hline & & & $\mathrm{Fe}$ & $\mathrm{Cr}$ & $\mathrm{Ni}$ & Mo & $\mathrm{Mn}$ & $\mathrm{Ag}$ & $\mathrm{Bi}$ \\
\hline \multicolumn{2}{|c|}{ Quantification limit } & & 1 & 0.5 & 3 & 3 & 0.3 & 1 & 5 \\
\hline \multirow{2}{*}{\multicolumn{2}{|c|}{$\begin{array}{l}\text { Initial metals used for } \\
\text { the preparation of LGE }\end{array}$}} & $\mathrm{Pb}$ & 68 & 17 & 9 & $<$ & 1 & 20 & 116 \\
\hline & & $\mathrm{Au}$ & 24 & $<$ & 3 & $<$ & $<$ & 34 & $<$ \\
\hline \multirow[t]{5}{*}{$400^{\circ} \mathrm{C}$} & \multirow[t]{2}{*}{$0 \mathrm{~h}$} & LBE & 18 & 1 & 2 & $<$ & $<$ & 5 & $/^{b}$ \\
\hline & & LGE & 29 & 7 & 6 & $<$ & 1 & 14 & 97 \\
\hline & $900 \mathrm{~h}$ & & 16 & 4 & 83 & $<$ & 2 & 26 & 114 \\
\hline & \multirow[t]{2}{*}{$1800 \mathrm{~h}$} & & 13 & 4 & 146 & $<$ & 3 & 26 & 139 \\
\hline & & LBE & 4 & 2 & 14 & $<$ & 0.3 & 5 & $/^{b}$ \\
\hline \multirow[t]{2}{*}{$450^{\circ} \mathrm{C}$} & \multirow[t]{2}{*}{$1300 \mathrm{~h}$} & LGE & 86 & 134 & 537 & $<$ & 53 & 25 & 106 \\
\hline & & LBE & 15 & 2 & 74 & $<$ & 0.4 & 5 & $/^{b}$ \\
\hline \multicolumn{3}{|c|}{$316 \mathrm{~L}$ stainless steel composition $[\%]^{a}$} & 64.3 & 17.4 & 13.1 & 2.6 & 1.7 & $<$ & $<$ \\
\hline
\end{tabular}

a: The precision for these data is in the range of $\pm 1 \%$;

b: not determined.

side the material test sections. The retrieved samples were finally analysed by SEM, the results of these investigations are reported elsewhere [12].

At the end of both test campaigns, samples of the two eutectics with masses ranging from 1 to $5 \mathrm{~g}$ were taken and transferred to PSI for chemical analysis. Within the first campaign, which was performed at $400{ }^{\circ} \mathrm{C}$, lead-gold eutectic samples were taken immediately after start-up of the loop $(0 \mathrm{~h})$, after $900 \mathrm{~h}$ and at the end of the first run $(1800 \mathrm{~h})$. LBE samples were obtained after start-up and at $1800 \mathrm{~h}$. For the second campaign at $450^{\circ} \mathrm{C}$, LGE and LBE samples were obtained after $1300 \mathrm{~h}$. No exchange of the liquid metals took place after the first test campaign, therefore, the measurement point at $450{ }^{\circ} \mathrm{C}$ comprises the time for the first run of $1800 \mathrm{~h}$ and $1300 \mathrm{~h}$ for the second one.

From each retrieved sample, approx. $250 \mathrm{mg}$ were cut and dissolved in $5 \mathrm{~mL}$ of $7 \mathrm{M} \mathrm{HNO}_{3}$. LGE required an additional dissolution step, as gold does not dissolve in nitric acid. It remained as a brown sludge and was separated from the solution by centrifugation. The sludge was washed twice with $5 \mathrm{~mL}$ of distilled water, again centrifuged, weighed and finally dissolved in $2 \mathrm{~mL}$ of aqua regia. Samples of pure $\mathrm{Pb}$ and $\mathrm{Au}$, which were used for the preparation of LGE, were analyzed as received from the supplier and dissolved in $7 \mathrm{M}$ $\mathrm{HNO}_{3}$ and aqua regia, respectively. Additionally, steel samples of $200 \mathrm{mg}$ were taken from the 316L tubing of the loop and dissolved in aqua regia.

For each analyzed sample, 4 measurements were made in order to decrease uncertainties. Together with blank solutions of $7 \mathrm{M} \mathrm{HNO}_{3}$ and aqua regia, used for background estimations, all aqueous solutions were analyzed via ICPOES. Before each measurement, the samples were diluted with $0.2 \mathrm{M}$ nitric acid solution. The elements of interest were $\mathrm{Fe}, \mathrm{Cr}, \mathrm{Ni}, \mathrm{Mo}$ and $\mathrm{Mn}$ as steel alloying elements as well as $\mathrm{Ag}$ and $\mathrm{Bi}$ (in case of LBE $\mathrm{Ag}$ only) as typi- cal impurities in LGE and LBE. Analysis was done using a Vista Pro AX simultaneous ICP-OE spectrometer from Varian Inc. Emission lines used for the determination of Fe, Cr, Mn and Mo were 238.20, 267.72, 257.61 and 202.03 nm, respectively. The concentration of $\mathrm{Ni}$ was calculated by averaging the counts at 216.56 and $231.60 \mathrm{~nm}$. For the determination of $\mathrm{Ag}$ and $\mathrm{Bi}$ the lines at 328.07 and $223.06 \mathrm{~nm}$ were used. Standard solutions of the analyzed elements were measured in order to perform a calibration of the spectrometer.

The final concentration of each element was calculated by averaging data over all repetition measurements, subtracting the background of the blank solutions.

\section{Results}

The concentrations of relevant trace elements found in both investigated alloys and their quantification limits are given in Table 1. Additionally, the measured composition of the structure material of the loop (316L stainless steel) is given.

The concentrations of $\mathrm{Ag}$ and $\mathrm{Bi}$ may be used to evaluate the precision of measurements in each experimental campaign. Silver is a noble metal that is easily dissolved in lead alloys [13]. This element is not present in relevant amounts inside the steel structure or the test specimens, nor does it precipitate from the liquid metal or adsorb on the steel tubing surface at the studied temperatures. In $\mathrm{Hg}$, it was indeed observed in laboratory experiments [14] and also in the Japanese SNS mercury target [15], that Ag remained dissolved in the liquid metal and did not adsorb to tubes and pipes. Similar behaviour was found concerning the Ag distribution in proton irradiated LBE retrieved from different positions of the solidified MEGAPIE target [16]. This implies that the concentration of Ag inside both liquid metals should not change over the whole period of test campaigns 


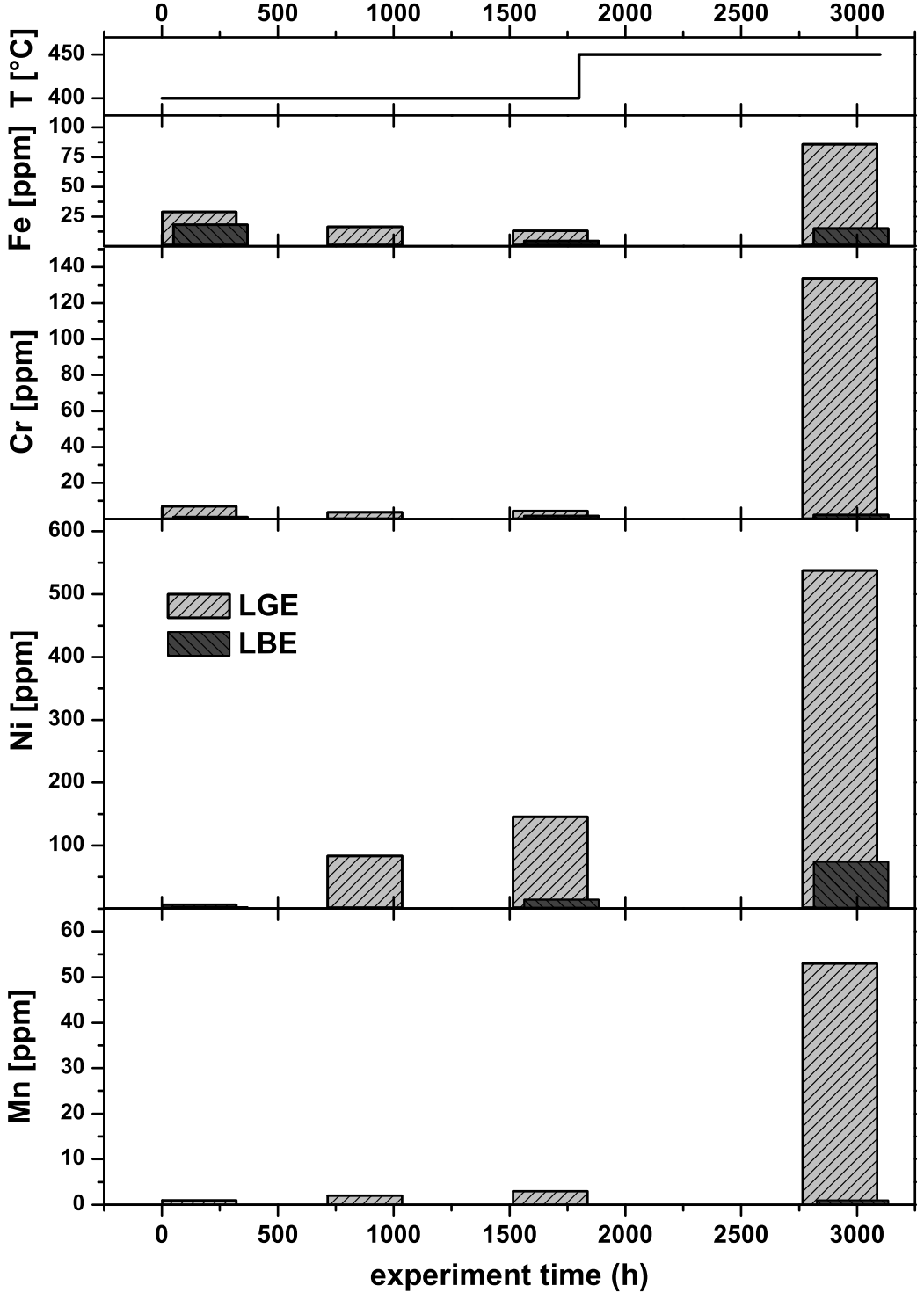

Fig. 2. The mass concentration of $\mathrm{Fe}, \mathrm{Cr}, \mathrm{Ni}$ and $\mathrm{Mn}$ in ppm found in LGE and LBE as a function of accumulated experiment time. In the upper section of the graph the operating temperature is shown, where the temperature offset represents a maintenance break for both loops. by dissolution or deposition processes. A similar postulate may be made for Bi dissolved in LGE because of its high solubility in $\mathrm{Pb}$ and $\mathrm{Au}$.

By averaging the measured concentrations, the mean impurity contents of $\mathrm{Ag}$ and $\mathrm{Bi}$ before starting the campaigns were calculated to be $5 \pm 1 \mathrm{ppm} \mathrm{Ag}$ in $\mathrm{LBE}$ and $23 \pm 6 \mathrm{ppm} \mathrm{Ag}$ and $114 \pm 18 \mathrm{ppm} \mathrm{Bi}$ in LGE. Both lastmentioned values coincide well with impurity concentrations found in $\mathrm{Pb}$ and $\mathrm{Au}$ before the preparation of LGE.

The determined concentrations for the most important steel alloying elements $\mathrm{Fe}, \mathrm{Cr}, \mathrm{Ni}$ and $\mathrm{Mn}$ are plotted against the accumulated operating time in Fig. 2. In addition, the operating temperature with time is shown in the upper section of the graph.

In the initial LGE material, 29 ppm Fe is found. The concentration of $\mathrm{Fe}$ is even higher in $\mathrm{Pb}$ used for the preparation of its alloy with gold. This contamination may originate from the mixing device used for preparing the lead-gold eutectic, where molten lead was in contact to steel structure materials at temperatures exceeding $500{ }^{\circ} \mathrm{C}$.

As indicated in Fig. 2, the dominant impurity that is preferentially dissolved in LGE is Ni. Its concentration continuously increases with operation time of the loop at $400{ }^{\circ} \mathrm{C}$.
Compared to LBE, there is a clearly larger dissolution effect of $\mathrm{Ni}$ - after $1800 \mathrm{~h}$ the concentration of $\mathrm{Ni}$ in LGE is ten times higher than in the bismuth containing alloy. The amount of Mn found in both liquid metals is generally low, and similar to $\mathrm{Ni}, \mathrm{Mn}$ is found in LGE in ten times higher concentration compared to LBE after $1800 \mathrm{~h}$ of operation. Interestingly, the concentration of $\mathrm{Fe}$ inside both loops decreases for longer operation times at $400{ }^{\circ} \mathrm{C}$. At the end of the first test campaign, the concentration of Fe in LBE decreases up to 5-fold if compared to the content present in the alloy before start-up.

The concentrations of corrosion products within both alloys considerably increase in the second loop experiment that was performed at a higher temperature $\left(450{ }^{\circ} \mathrm{C}\right)$. Here, again LGE affects the steel structure more strongly than $\mathrm{LBE}$, resulting in concentrations of $86 \mathrm{ppm}$ for $\mathrm{Fe}, 53 \mathrm{ppm}$ for $\mathrm{Mn}, 134 \mathrm{ppm}$ for $\mathrm{Cr}$ and $537 \mathrm{ppm}$ for Ni. The dissolution of impurities from the steel matrix into the liquid metal at $450{ }^{\circ} \mathrm{C}$ is far less pronounced in LBE; however, significant dissolution of nickel is also observed. For both investigated alloys, this element is the dominating impurity. No Mo dissolution was found either in LGE or in LBE. 


\section{Discussion}

From investigations on the corrosion behaviour of LBE it is known that the concentration of oxygen dissolved in the alloy is a crucial factor influencing the corrosion behaviour [17]. Since no oxygen sensor was installed in either of the loops, a detailed analysis of the underlying mechanisms is not possible in the present study. Therefore, in this paper we simply compare results concerning impurities dissolved from the steel matrix between the two liquid metals.

The origin of impurities inside both liquid metals, apart from those present already at the beginning, is mainly the twin-loop tubing material. The contact area of the stainless steel $316 \mathrm{~L}$ tubing of the loop towards the liquid metal is much higher if compared to that of specimens within the test section. Considering an inner diameter of $10 \mathrm{~mm}$ and a total length of the loop of approximately $2.5 \mathrm{~m}$, the total contact area would correspond to about $800 \mathrm{~cm}^{2}$. The size of the steel specimens inside the material test section is comparatively small ${ }^{2}$. Thus, the contribution from the test specimen is negligible and the source of steel alloying elements that are found as impurities either in LBE or LGE should mainly be the tubing material.

In order to understand the behaviour of these corrosion products in LBE and LGE at different temperatures, knowledge on their solubility in these media is of major importance. Literature data on the solubility of $\mathrm{Fe}, \mathrm{Cr}$ and $\mathrm{Ni}$ is available for lead, bismuth and their eutectic alloy [18]. For $\mathrm{Mn}$ and $\mathrm{Mo}$, data is only available for pure $\mathrm{Pb}$ and $\mathrm{Bi}$, not for LBE. Therefore, we will focus our discussion on the dissolution behaviour of $\mathrm{Fe}, \mathrm{Cr}$ and $\mathrm{Ni}$.

The solubility of $\mathrm{Ni}$ and $\mathrm{Cr}$ in LBE was recently determined in [18] and [19], and data in the temperature range of $350-450{ }^{\circ} \mathrm{C}$ is available. From temperature functions published in these papers, it may be concluded that $\mathrm{Ni}$ is the most soluble species of the discussed elements, with solubility limits ranging from $10^{4}$ to $2 \times 10^{4} \mathrm{ppm}$ at 400 and $450{ }^{\circ} \mathrm{C}$, respectively. The solubility function for $\mathrm{Cr}$ yields much lower values for these temperatures, ranging from 4 to $8 \mathrm{ppm}$. To estimate solubility data for $\mathrm{Fe}$, an extrapolation from functions obtained at higher temperatures [20] has to be made. From such extrapolation, a solubility of $\mathrm{Fe}$ in LBE in the order of $1 \mathrm{ppm}$ at the highest investigated temperature of $450{ }^{\circ} \mathrm{C}$ is obtained. This is much lower than the values found and could possibly explain the observed 5-fold decrease in $\mathrm{Fe}$ concentration at $400{ }^{\circ} \mathrm{C}$. The solubility of Mo in molten $\mathrm{Pb}$ and $\mathrm{Bi}$ was determined to be below $1 \mathrm{ppm}$ for temperatures up to $1000{ }^{\circ} \mathrm{C}$ [21]. Thus, the fact that no Mo was found in our analysis is not surprising.

There are no data on the solubility behaviour of these chemical elements in a lead-gold alloy. It is however well known that gold easily forms stable alloys with several metals like $\mathrm{Ag}$ and $\mathrm{Cu}$ (jewellery), but also with $\mathrm{Ni}, \mathrm{Fe}$, $\mathrm{Al}, \mathrm{Cr}$ and others [22]. Some of these metals show miscibility with gold in wide concentration ranges above its melting temperature. Thus, one could suspect that the presence of $15.2 \mathrm{wt}$ \% gold could cause higher solubilities of these elements in LGE compared to LBE.

\footnotetext{
${ }^{2}$ In total, 6 specimens with about $1 \mathrm{~cm}^{2}$ per specimen were installed per test section. In both loops the same test specimen were employed.
}

Apart from the knowledge on the solubility of these elements in a liquid metal alloy, information on the rate at which a solid goes into solution is of importance. Eq. (1) describes the dissolution kinetics of a solid in a liquid metal under isothermal conditions [23]:

$$
\frac{\mathrm{d} c}{\mathrm{~d} t}=\frac{\alpha S}{V_{1}}\left(c_{\mathrm{s}}-c_{\mathrm{v}}\right)
$$

where $S$ is the total surface of the solid in contact with a liquid metal of volume $V_{1}$ with a concentration $c_{\mathrm{v}}$ of the solute. The value $c_{\mathrm{s}}$ denotes the saturation concentration (solubility) of the solute in the liquid metal and $\alpha$ the temperature dependent dissolution rate. If $c_{\mathrm{v}} \ll c_{\mathrm{s}}$, the concentration increase per unit of time becomes proportional to the saturation concentration $c_{\mathrm{s}}$, assuming $S, V_{1}$ and $\alpha$ remain constant.

Indeed, for $\mathrm{Ni}$ in LGE, the data obtained for $400{ }^{\circ} \mathrm{C}$ show an approximately linear behaviour. This finding indicates that in LGE the concentration observed in the present experiments are far below the saturation concentration for this element at $400^{\circ} \mathrm{C}$. In case of LBE, the solubility data given above also show no $\mathrm{Ni}$ saturation at $400^{\circ} \mathrm{C}$ and $450^{\circ} \mathrm{C}$. From the available data it is concluded, that much longer test runs are needed in order to obtain Ni saturation.

The dissolution of alloying elements from the steel surface is a relatively slow process dependent on the temperature and time of contact with the liquid metal. It will unavoidably result in their depletion from the steel surface. Such depletion was in fact observed for $\mathrm{Ni}$ and $\mathrm{Mn}$ during investigations of the SS 316LN specimens from the material test sections from the twin-loop. It was shown by SEM combined with energy dispersive X-ray analysis that for SS $316 \mathrm{~L}$ specimens in contact to LGE a depletion of Ni content from 10.2 wt. \% to 2 wt. \% had occurred at the surface of the specimen throughout a penetration layer of 10-40 $\mu \mathrm{m}$ [12]. Since the loops were operated isothermally, a similar depletion can be expected for the inner tubing surfaces of the whole LGE loop.

The decrease in the concentration of Fe in LGE during the experiment at $400{ }^{\circ} \mathrm{C}$ may indicate that this element was already present at the start of the experiment at concentrations exceeding the saturation solubility. These high concentrations at start-up can be explained by an extended contact of the lead used for preparation of the eutectic alloy with the surface of a steel melting pot at temperatures higher than $500{ }^{\circ} \mathrm{C}$. However, the decrease in $\mathrm{Fe}$ concentration could also be explained by the formation of magnetic iron clusters in the liquid metal that are precipitated within the electromagnetic pump. Such cluster formation was actually observed in mercury, where cluster growth inside the liquid metal is occurring on the submicron scale [24]. Together with $\mathrm{Cr}$, these clusters might then be trapped by magnetic forces near the pump. For example, high concentrations of $\mathrm{Fe}-\mathrm{Cr}$ agglomerates were found for samples retrieved near the electro-magnetic pump of the JLBL-1 loop [25], supporting this assumption.

\section{Summary of the results and evaluation of LGE as potential target material}

The leaching of steel alloying elements from 316L stainless steel in contact with liquid lead-gold eutectic is significantly 
stronger compared to that observed in LBE at similar operational conditions. Substantial dissolution of nickel was observed at temperatures of 400 and $450{ }^{\circ} \mathrm{C}$. The observed strong corrosion prohibits the use of LGE by simply substituting LBE in a facility equipped with $316 \mathrm{~L}$ stainless steel. A further consideration of LGE as target material would call for detailed investigations looking for structure materials with higher resistance towards LGE. For example, Mo shows a relatively high resistance towards liquid metal alloys. Based on its known resistance to lead, it has been actually already applied very successfully as construction material for a lead loop at the neutron time of flight facility at HZDR [26]. Another possibility to mitigate corrosion implies a protection by special coatings resistant to liquid metal deterioration [23]. These investigations should be performed under controlled conditions concerning the purity of the alloy. All material and corrosion studies have also to incorporate reliable measurements of the oxygen concentration inside the liquid metal, as this was found to be a crucial factor for material corrosion in LBE systems [23].

Finally, material tests have to be performed under irradiation conditions. Material damage should be investigated to assure reliable statements on the sustainability of these materials under an intense irradiation environment present in a spallation target.

Apart from research on the corrosion resistance, the physico-chemical behaviour of spallation and activation products in a LGE target would have to be investigated as well. Calculations in [11] revealed that after proton irradiation of LGE the polonium inventory will be by a factor of $10^{4}$ smaller if compared to the bismuth based alloy. These calculations assumed that LGE is free from bismuth. From lead refining it is known that $\mathrm{Bi}$ is a prominent impurity present in cast $\mathrm{Pb}$. Our measurements have shown that the Bi content in LGE used for the present investigation exceeds $100 \mathrm{ppm}$. The amount of polonium formed within LGE with such a concentration of $\mathrm{Bi}$ would be certainly higher than predicted by [11].

Another peculiarity of LGE arises from the formation of mercury due to nuclear transmutation of gold. Since LGE as a target material requires operating temperatures of about $100 \mathrm{~K}$ higher than LBE, the evaporation rates of radionuclides formed within the liquid metal will be enhanced. As a result, the total release of isotopes of $\mathrm{Hg}$ could be higher from LGE if compared to the lead-bismuth alloy, whereas the Po release may not be necessarily lower due to the higher operating temperatures. Consequently, dedicated studies on the release of volatiles from LGE are mandatory and cover gas filtering systems have to be developed in order to assure a safe operation of the spallation facility.

Summarizing all these constraints and taking into account that LGE is up to now only very rarely investigated, one has to expect extended R\&D programs for several decades to provide the necessary information for a safe operation in a nuclear facility. For comparison, the reader may look up the extensive studies on LBE performed since the early 1950ies [23]. Another drawback concerning this material is that there is no other industrial application that would justify such expensive and time-consuming research projects. Together with the high costs of gold, a potential use of LGE as target material for spallation neutron sources seems not to be reasonable from the present point of knowledge.

Acknowledgment. The research leading to these results has received funding from the European Community's Seventh Framework Programme (FP7/2007-2013) under Grant Agreement No 202247 "NeutronSourceESS". We thank Dr. Y. Dai for stimulating discussions on the presented topic. The Paul Scherrer Institute is acknowledged for the overall use of the facilities.

\section{References}

1. Bauer, G. S.: Physics and technology of spallation neutron sources. Nucl. Instrum. Methods Phys. Res. A 463, 505-543 (2001).

2. McManamy, T., Forester, J.: SNS Target Systems initial operating experience. Nucl. Instrum. Methods Phys. Res. A 600, 25-27 (2009).

3. Futakawa, M., Haga, K., Wakui, T., Kogawa, H., Naoe, T.: Development of the $\mathrm{Hg}$ target in the J-PARC neutron source. Nucl. Instrum. Methods Phys. Res. A 600, 18-21 (2009).

4. http://ess-scandinavia.eu/.

5. Chiriki, S., Fachinger, J., Moormann, R., Hinssen, H. K., Bukaemskiy, A., Odoj, R.: Decommissioning and safety issues of liquidmercury waste generated from high-power spallation sources with particle accelerators. Nucl. Technol. 168, 264-269 (2009).

6. Wagner, W., Groeschel, F., Thomsen, K., Heyck, H.: MEGAPIE at SINQ - The first liquid metal target driven by a megawatt class proton beam. J. Nucl. Mater. 377, 12-16 (2008).

7. http://myrrha.sckcen.be/.

8. Agostini, P., Baicchi, E., Zucchini, A., Benamati, G.: The recrystallization issue in lead-bismuth technology. J. Nucl. Mater. 335, 275-279 (2004).

9. Legendre, B., Souleau, C.: Phase equilibrium diagram of binary system gold-lead. Bull. Soc. Chim. France I, 2202-2206 (1973).

10. Moormann, R., Medarde, M., Platacis, E., Thomsen, K.: Proceedings of the International Workshop of Technology and Components of Accelerator Driven Systems, Karlsruhe, Germany, 15-17 March (2010).

11. Medarde, M., Moormann, R., Frison, R., Puzniak, R. J., Pomjakushina, E., Conder, K., Platacis, E., Dai, Y., Kiselev, D., Zanini, L., Torok, S., Zagyvai, P., Heinitz, S., Neuhausen, J., Schumann, D., Thomsen, K.: Lead-gold eutectic: An alternative liquid target material candidate for high power spallation neutron sources. J. Nucl. Mater. 411, 72-82 (2011).

12. Dai, Y., Gao, W., Zhang, T., Platacis, E., Heinitz, S., Thomsen, K.: A comparative study on the compatibility of liquid lead-gold eutectic and liquid lead-bismuth eutectic with T91 and SS 316LN steels. J. Nucl. Mater. 431, 113-119 (2012).

13. Hultgren, R., Desai, P. D., Hawkins, D. T., Gleiser, M., Kelley, K. K.: Selected values of the thermodynamic properties of binary alloys. American Society for Metals, Metals Park, Ohio (1973).

14. Neuhausen, J., Schumann, D., Dressler, R., Eichler, B., Horn, S., Stora, T., Eller, M.: Radiochemical aspects of liquid mercury spallation targets. J. Nucl. Mater. 431, 224-234 (2012).

15. Kai, T., Ooi, M., Kasugai, Y., Wakui, T., Kogawa, H., Haga, K., Hanano, K.: Proceedings $19^{\text {th }}$ Meeting on Collaboration of Advanced Neutron Sources, ICANS XIX, Grindelwald, Switzerland, 8-12 March (2010).

16. Neuhausen, J.: Personal communication.

17. Zhang, J. S., Li, N.: Review of the studies on fundamental issues in LBE corrosion. J. Nucl. Mater. 373, 351-377 (2008).

18. Martinelli, L., Vanneroy, F., Rosado, J. C. D., L'Hermite, D., Tabarant, M.: Nickel solubility limit in liquid lead-bismuth eutectic. J. Nucl. Mater. 400, 232-239 (2010).

19. Courouau, J.-L.: Electrochemical oxygen sensors for on-line monitoring in lead-bismuth alloys: status of development. J. Nucl. Mater. 335, 254-259 (2004).

20. Weeks, J. R., Romano, A. J.: Liquidus curves and corrosion of Fe, $\mathrm{Ti}, \mathrm{Zr}$ and $\mathrm{Cu}$ in liquid $\mathrm{Bi}-\mathrm{Pb}$ alloys. Corrosion 25, 131-136 (1969). 
21. Madelung, O. (Ed.): Landoldt-Börnstein, Numerical Data and Functional Relationships, Volume 5: Phase Equilibria, Cristallographic and Thermodynamic Data of Binary Alloys. SpringerVerlag Berlin, Heidelberg, New York, London, Paris, Tokyo, Hong Kong Barcelona, Budapest.

22. Cretu, C., van der Lingen, E.: Coloured gold alloys. Gold Bull. 32, $115-126$ (1999).

23. Handbook on Lead-bismuth Eutectic Alloy and Lead Properties, Materials Compatibility, Thermal-Hydraulics and Technologies. OECD Nuclear Energy Agency, Issy-les-Moulineaux (2007).
24. Luborsky, F. E.: The kinetics of growth of spherical Iron crystallites in mercury. J. Phys. Chem. 61, 1336-1340 (1957).

25. Kikuchi, K., Saito, S., Hamaguchi, D., Tezuka, M.: Ni-rich precipitates in a lead bismuth eutectic loop. J. Nucl. Mater. 398, 104-108 (2010).

26. Klug, J., Altstadt, E., Beckert, C., Beyer, R., Freiesleben, H., Galindo, V., Grosse, E., Junghans, A. R., Legrady, D., Naumann, B., Noack, K., Rusev, G., Schilling, K. D., Schlenk, R., Schneider, S., Wagner, A., Weiß, F.-P.: Development of a neutron time-of-flight source at the ELBE accelerator. Nucl. Instrum. Methods A 577, 641 (2007). 